\title{
The Impact of Gender Based Violence on Child Development in Livingstone District of Zambia
}

\author{
Article by Chanda Florence \\ Texila American University \\ E-mail: florencemulanshoka@gmail.com
}

\begin{abstract}
Gender based violence exposure happens in different social contexts of children's lives including families and communities. This often occurs in different form of violence exposures. Children are likely to be exposed to violence at a tender age and when they grow a bit old. In Zambia, Children in highdensity populated areas are disadvantaged and are more exposed to violence. For young children, it has been identified that where violence affects the one who is taking care of the child it means the child will be affected too. As the child grows with this violence exposure, the child's social, mental, emotional and academic performance out comes may be affected.

Children's exposure to violence has received less attention than of older children, it is an especially important developmental period when children are developing social and cognitive skills and preparing for transition to formal schooling. Gender based violence can be the evil in terms of child development.

Violence exposure in the lives of children can include different ways of which children experience. This can be within the family and the community and this affects the physical, emotional and mental development in a child.

In Zambia, Gender-based violence' is a form violence that has come on the scene and very common. This has brought problems in most people's lives and causing children to suffer also and in some cases, children ending up to be living on the streets resulting in street children and poor performance in school, in some cases children even drop out of school. Gender based violence is mostly inflicted by men on women. Women are the most victims of gender-based violence and this leads children to be exposed to different forms of violence. This is so because most of the time women are always with the children.

When young children are exposed to violence in the community and in their families, their behavior out comes is questionable. According to the ministerial, report by the Minister of Gender 2015 states, "Children who witness or are the victims of violence may learn to believe that violence is a reasonable way to resolve conflict between people. Boys who learn that women are not to be valued or respected and who see violence directed against women are more likely to abuse women when they grow up.
\end{abstract}

Keywords: Gender, Gender based violence, Child development, Impact, Witnessing, Hearing.

\section{Introduction}

This article reviews 'The impact of Gender based violence on Child development in Livingstone District of Zambia". Exposure to violence at a tender age increases the risk for polluted nation. Children who experience this violence grow up to hate and will have no feelings for others. This increases the high rate of school dropouts and hard-core criminals.

Women have the ability to promote a positive, constructive environment, but in order to do so they need social support from all circles. Women who are in a psychologically or physically abuse relationship with an intimate partner, possibly because of reasons explained through the Intergenerational Transmission Theory, are at least twice as likely to exhibit abuse towards their children than those women who have a healthy, supportive relationship with their partner (Mapp, 2006). Women who are depressed have a diminished ability to parent effectively; these mothers have difficulty communicating with their children and have more naturally negative interactions with them. The family environment of a depressed mother is often hostile, aggressive, and rejecting (Mapp, 2006). 
DOI: 10.21522/TIJAR.2014.06.01.Art002

ISSN: $2520-3088$

\section{Method}

To collect data the observation, qualitative and quantitative method will be used to establish the factors on the impact of Gender based violence on child development. My contention is that both quantitative and qualitative research approaches are appropriate for a case study in educational research (Strauss and Corbin, 1990; Patton, 2002), which deals with life skills. Both qualitative and quantitative methods are concerned with studying phenomena (Lbarkkin and Kurdziel, 2002). However, case study research is primarily concerned with gaining direct experience with a setting is intrinsically and exploratory endeavor (Mann, 2003). Thus, it has the potential for generating new theories and idea and is therefore particularly applicable to my study. I will collect quantitative data in the form of transcripts and descriptions while at the same time I will also collect data that could be measured and represented in numbers. However, all the quantifiable data is to be interpreted qualitatively. As early childhood educators, we all have our own philosophies and approaches to education. Our approach to teaching is created from a multitude of resources and probably includes knowledge from early childhood theorists, an understanding of child development and our experiences with children in different learning environments. It is worthy to seek information that would assist teachers, caregivers, parents to become practitioners that are more reflective in their daily rearing of child.

As a practicing teacher, I have an active interest in disseminating the information on prevention and the skills to reduce gender-based violence. This will provide technical and normative guidance for evidence-based gender-based prevention. It advocates for increased international support for and investment in evidence-based gender-based violence prevention.

\section{Discussion}

In Zambia, Gender based violence has become the order of the day. the most affected is the woman who is the care giver of the child. This violence is transferred to an innocent child who is going to have behavioural problems. The nation has been faced with such an overwhelming crisis that dramatic measures were called for, and large numbers of police officers, social welfare officers, doctors and ordinary people have been called to help in the eradication of this evil Gender based violence and deal with the massive prevention which has already had a major impact on child development. When a child is exposed to all forms of violence poses a new challenge. This brings a negative impact on the development of a child.

Every day in Livingstone Teaching Hospital (LTH) in Livingstone, there are women, girls and men who are struck down by violence and every day we are faced with the consequences of bad child behavior and poor performance in academic circles.

In order to eradicate Gender based violence, Enforcement Mechanisms and Support Systems have been put in place in Zambia, such as protecting children from violence exposure and strengthening families, counselling families, supporting families, protective factors, public awareness, community activities, positive parenting, intervention programs, and more.

This means that we need to Promote rights of women and girls, across the country so that it can be effective in achieving the desired goal, which is to improve the life style of a woman who is a care giver of a child.

According to Chidoori Rumbidizai the Government has also reviewed laws such as the penal code to increase protection of women and children from sexual violence and also developed the National Gender Policy 2014 based on the review of the National Gender Policy of 2000. The National Plan of Action on Gender Based Violence (NPA-GBV) 2010-2014 lays out the government's commitment to eliminate GBV. Civil society and several non-governmental organizations have played a pivotal role in ensuring adequate protection for women.

Gender based violence programmes is well received as is evidence from how fast it's spreading. The way to credit its contribution as an exercise is through research. Research will offer facts that can encourage our society to make informed decisions and for professionals to use it for the benefit of their clients. New knowledge can be used to formulate laws.

The societal effects of gender-based violence are often understood better when looking at the effects of the violence on children. The controversial issue of child custody might be a good start before 
discussing the overlap between violence against women and children. When women suffer violence in a partnership, children are also affected in different ways.

Children need their father, even if he is a batterer. Some abusers are good fathers and should have joint custody of their children.

Male children who see their father beat their mother are 7 times more likely to be violent as adults than those who did not witness such violence (Straus et al., 1981). Children need healthy role models. Unhealthy role models damage children now and in the future. Men who batter women are more likely to batter children physically, sexually, and emotionally. Their need for power and control of family members often stifles the healthy development of their children.

Nearly $90 \%$ of children who grow up in abusive homes witness the assaults. Nearly half of the batterers also abuse their children. (MINCAVA 2004: Family Violence Nursing Curriculum)

Gender based violence in young children in particular; the consequences may become lifethreatening extending in adulthood and cause health problems. The same children who are exposed to violence are at high risk of developing a series of behavioral, cognitive and emotional problems that may persist into adulthood.

A woman can experience violence through the factors such as poverty financial dependence, disability, homelessness or insecure status that can increase the risk of caring for the child.

According to the ministerial statement of 2017, "The ministry is committed to creating an enabling environment in which civil society organisations, faith based organisation, private sector and individuals can work and thrive and hence, contribute to the reduction of GBV cases and incidences of child marriage to make the lives of our people worth living".

Gender-based violence includes domestic abuse, rape and sexual assault, childhood sexual abuse, commercial sexual exploitation, stalking and harassment, and harmful traditional practices (e.g. female genital mutilation, 'honour' crimes and forced marriage). It predominantly affects women, although men too can be victims of abuse.

Children who are exposed to battering become fearful and anxious. They are always on guard, watching and waiting for the next event to occur. They never know what will trigger the abuse, and therefore, they never feel safe. They are always worried for themselves, their mother, and their siblings. They may feel worthless and powerless.

Children who are early exposed to violence grow up with anger, fear, guilt, shame, sleep disturbances, sadness, depression, and anger and are expected to keep the family secret; sometimes they do not even talk to each other about the abuse. Children from abusive homes can look good to the outside world, but inside they are in terrible pain. Their families are chaotic and crazy. They may blame themselves for the abuse thinking if they had not done or said a particular thing, the abuse would not have occurred. They may also become angry at their siblings or their mother for triggering the abuse. They may feel rage, embarrassment, and humiliation.

Children of abuse feel isolated and vulnerable. They lack attention, affection and approval. Because mother is struggling to survive, she is often not there for her children, because the father is so consumed with controlling everyone, he also is not there for his children. These children become physically, emotionally and psychologically abandoned.

Gender-based violence has become an umbrella term for any harm that is perpetrated against a person's will, and that results from power inequalities that are based on gender roles. Around the world, gender-based violence usually has a greater negative impact on women and girls.

Gender based violence can have serious and lasting effects on children's growth, development, health and wellbeing and contribute to health inequalities in adulthood.

Being a witness of domestic violence is especially stressful for children as they are deprived of the fundamental needs for safety and comfort and grow up in an atmosphere of fear and terror. Children feel helpless, unprotected, responsible, or partly to blame or they want to interfere and get injured themselves. Particularly when the woman is exposed to constant violence the consequences can be traumatic and this is transferred to an innocent child who is growing.

Witnessed or directly experienced violence has various effects on girls and boys. Such experiences can impair the emotional, physical and cognitive development of the affected children and in the case of chronic forms of violence or with very small children can lead to traumatic damages. Research found 
DOI: 10.21522/TIJAR.2014.06.01.Art002

ISSN: $2520-3088$

that $50 \%$ to $70 \%$ of children exposed to domestic violence suffer from posttraumatic stress disorder (Klotz 2000).

In the case of co-experienced partner violence, studies of child behavior disorders show outward directed reactions such as anxiety and aggressiveness ("Externalization"). However, most of all they show inward directed reactions such as intense depressiveness or fearfulness ("Internalization"; Kindler 2002). Kindler determined that compared to control groups, children affected by domestic violence show a five- fold risk of symptoms that require treatment (ibid).

According to Kerig (1998) regarding gender-specific differences indicates that girls are more inclined to feel partly responsible for violence, whereas boys feel a stronger sense of threat. Girls showed externalized symptoms in the immediate social environment but the danger of chronic externalization signs was thought to be higher for boys.

Evidence on the prevalence and forms of GBV has expanded rapidly in recent years, although data mostly come from high-income countries and are sparse in several regions. More population-based research is needed in order to create a clearer picture of GBV around the world. Currently there is very little research on the prevalence and complexities of some forms of violence like trafficking, rape, honor killings, child marriage and abuse, and violence in conflict settings. There is also a limited understanding of the various experiences a woman may have with GBV over her lifetime and what services and supports she might need at different points. More can be done to capture the range of experiences and their short-term and long-term health and social consequences for women. (Fulu, E., and L. Heise 2014).

It has come to light that very little has been done in terms of children exposure to violence and the impact gender-based violence has on child development. More studies need to be done in order to have comparable results from which conclusions can be made about the impact of gender on child development in Zambia.

In Livingstone town of Zambia, most women suffer gender-based violence. There are factors that lead to gender-based violence. Several factors that increase the risk of a man committing violence and the risk of a woman experiencing violence. This has to be established in order to get to the root cause.

\section{Summary}

The root cause of gender-based violence lied in unequal power relations between women and men. However, a variety of factors on the individual level, the family level, and at the level of community and society, often combine to raise the likelihood of violence occurring.

Children who are raised in abusive homes learn that violence is an effective way to resolve conflicts and problems. They may replicate the violence they witnessed as children in their teen and adult relationships and parenting experiences. Boys who witness their mothers' abuse are more likely to batter their female partners as adults than boys raised in nonviolent homes. For girls, adolescence may result in the belief that threats and violence are the norm in relationships.

The behavioral responses of children who witness domestic violence may include acting out, withdrawal, or anxiousness to please. The children may exhibit signs of anxiety and have a short attention span, which may result in poor school performance and attendance. They may experience developmental delays in speech, motor or cognitive skills. They may also use violence to express themselves displaying increased aggression with peers or mother. They can become self-injuring.

The study can contribute to the formulation of policies related to prevention of Gender based violence and in the strengthening of child development. By so doing this will improve the

Research into the nature and effectiveness of the programs that Zambians are already engaging into is important even as we look forward to the implementation of interventions related to impact of genderbased violence on young children.

\section{Results}

Parents bring up their children in different ways, which influence the children's, social, emotional and intellectual development. Some parents do not offer much on the moral and social values that a child needs to uphold acceptable social behavior of society. 
Early childhood Education enables all children to develop the skills that children require for their holistic development. These skills can easily attain through taking care of the children by keeping them away from early exposure of gender-based violence. Another way is by identifying causes and risk factors that lead to Gender based violence.

Also designing and testing interventions that are aimed at minimizing the risk factors of child abuse. Another way to prevent Gender based violence is by disseminating information about the effectiveness of interventions and increasing the scale of proven effective interventions.

Children must be reared in a loving and caring environment and distance them from early exposure to any form of violence. Let the children get motivated as they freely choose to participate and enjoy what they feel they can do without any interference from the parents or care givers. Children will therefore learn to work independently and they develop positive attitude'

Avoid Early Violence exposure it is not the right way of rearing the children. Just by talking and showing love between mother, father, family and the community at large. When you really care for them can reduce the neglect or child abuse, therefore children will definitely develop positive attitude and there are chances for building self-confidence and all other areas of child development.

Children, who experience gender-based violence, are mentally affected and fail to learn to work freely and independently. This lessens the opportunity for a teacher to carry out the opportunity to diagnose and assess the learning in a non-threatening situation.

\section{Conclusion}

This study intends to find out the consequences and prevention of Gender based violence on child development in line with promoting the wellbeing of the child. In carrying out the objectives to help as a yardstick to achieve the intended purpose, appropriate data-collecting instruments is be used to design in line with the objectives

The study aims at establishing factors whether parents, teachers, caregivers and the community help children to enhance child development by preventing Gender based violence. The researcher felt it worthy to seek information that would assist teachers, caregivers, parents and the community to become practitioners that are more reflective in their daily rearing of children. The study is further to provide information to policy makers to understand the consequences of Gender based violence $t$ and the importance of child development. This study is contributing to my understanding of the teacher's experiences as they progress through the training and implementation cycle in their classroom experiences. Schlechy (1990) stated "to improve schooling, one must invest in people, support people and develop people" (p.38). Educational practitioners can be liberated to improve their profession with opportunities that promote systemic, collaborative teacher research conducted in the authentic setting of the classroom. Educators can use teachers to uncover explanations to their own questions about the best way to avoid violence and improve on rearing children in a conducive environment.

As a practicing teacher, I have an active interest in disseminating the information on prevention and the skills to reduce Gender based violence and provide technical and normative guidance for evidencebased on prevention.

It advocates for increased international support for and investment in evidence-based child maltreatment prevention. It also provides technical

support for evidence-based child abused prevention programs in several low and middle-income countries.

"Global status report on violence prevention 2014", the report reviews the current status of violence prevention efforts in countries, and calls for a scaling up of violence prevention programs; stronger legislation and enforcement of laws relevant for violence prevention; and enhanced services for victims of violence. It is in this vein that this research finding will add to the body of knowledge and benefit others that may be in the same predicament as me. 
DOI: $10.21522 / \mathrm{TIJAR} .2014 .06 .01 . A r t 002$

ISSN: $2520-3088$

\section{References}

[1]. Achenbach, T. (1991). Manual for the Child Behavior Checklist, University Associates, Burlington, VT.Google Scholar.

[2]. Augustyn, M., Parker, S., Groves, B. M., and Zuckerman, B. (1995). Children who witness violence. Contemp. Ped. 12: 35-57.Google Scholar.

[3]. Baron, R. M., and Kenny, D. A. (1986). The moderator-mediator variable distinction in social psychological research: Conceptual, strategic, and statistical considerations. J. Personal. Social Psychol. 51: 1173-1182.Google Scholar.

[4]. Basic Behavioral Science Task Force of the National Advisory Mental. Health Council. (1996a). Basic behavioral science research for mental health: Vulnerability and resilience. Am. Psychologist 51: 22-28.Google Scholar.

[5]. Ellsberg, M., D. J. Arango, M. Morton, et al. (2015) Prevention violence against women and girls: what does the evidence say? Violence against women and girls 1.

[6]. The Lancet [published online]. 4. Garcia-Moreno, C., C. Zimmerman, A. Morris-Gehring, et al. (2015) Addressing violence against women: a call to action. Violence against.

[7]. Ministerial statement on Gender Based Violence in Zambia March 2017. Assessed on internet On 2nd November 2018. 